\title{
Changing the geometry of the Wind Tower and its Influence on Aerodynamic Behavior and Natural Ventilation
}

\author{
Moussaoui Abdeljabar ${ }^{1}$, Sakhri Nasreddine ${ }^{2}$, Draoui Belkacem ${ }^{3}$, \\ Rahmani Lakhdar ${ }^{4}$, Bensafi Mohamed ${ }^{5}$ \\ ENERGARID Laboratory of Energy in Arid zones, Faculty of Technology. \\ TAHRI Mohammed University Bechar Algeria
}

\begin{abstract}
The wind tower is an ancient technique used since the time of Feraoun (1300 AC) until today for natural ventilation in the arid Middle East region including Iraq and Iran without any energy consumption ensuring thermal comfort and considerable energy efficiency by comparing it with HVAC systems (Heating, Ventilation and Air-Conditioning) widely used in these areas. Two mechanisms are used in the natural ventilation: buoyancy caused by the temperature difference and the wind pressure forces on the envelope of the ventilated structure. $\Delta p$ is the pressure difference resulting from the external pressure caused by the interaction wind-structure and the internal pressure which cause an airflow inside building driving by $\Delta p$ and finally the air leave the building through building openings (doors, windows, etc.). In order to create maximum pressure difference, the wind tower geometry (windward side) is questioned. Four aerodynamic shapes are studied: square, circular, triangular and $U$. The results show that the circular and triangular models have external and internal pressures much higher than the square and $U$ model. This new aerodynamic geometries are more appropriate to create maximum $\Delta p$ than rectangular tower. These results confirm the importance of Computational Wind Engineering CWE in the study of natural ventilation potential of this technique especially in windy arid regions such as the South of Algeria. CFD techniques have become increasingly essential as an aid to decision in modern design of natural ventilation systems.
\end{abstract}

Keywords: Natural ventilation, wind tower, fluid-structure interaction, aerodynamic shape, CFD.

\section{Introduction}

Thermal comfort is a recognized and justified request in buildings because of its impact on the quality of indoor environments, health and productivity of the occupant from three-quarters of his time inside. This request is supported by standards and regulations that ensure compliance of indoor environments with thermal comfort requirements. But research consistent and comfortable indoor thermal

environment in accordance with standards, throughout the year and regardless of climatic peculiarities of the site, buildings ... accompanied by an increase in climate systems, resulting in high energy consumption, fossil basically, exhaustible and polluting. [1]

In Algeria, the residential sector represents the largest energy consumption by $42 \%$ of national energy consumption [2]. Big amount of this energy is provided to ensure thermal comfort especially in hot, arid regions like the south of Algeria. The use of HVAC equipment represents the largest end-use in residential buildings and offices, nearly two-thirds of total energy consumption [3-4].
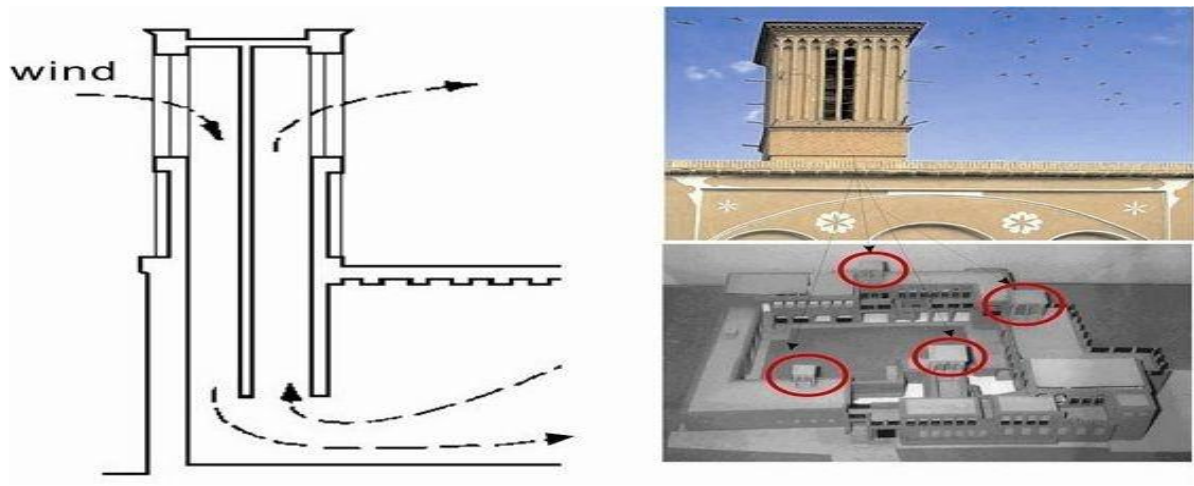

Fig.1 Wind Tower

Ventilation can have two sources: natural or mechanical. Mechanical ventilation can be effective and controlled, but it represents $25 \%$ of energy consumption in the building ventilated mechanically [5]. 
Natural ventilation is a passive cooling strategy because of the large potential for reducing energy consumption, in promoting air quality and thermal comfort satisfying [6-7-8-9].

It is defined as air infiltration into the building through openings and internal movement (air flow) caused by the pressure gradient due to wind and buoyancy effects and it has a large depends on the weather conditions of the region.

Etheridge [10] divide the natural ventilation of a building into two parts: the envelope flow (how air moves in and out) and the movement of air inside. The envelope flow is generated from the differences in pressure across the envelope generated by the wind and the differences in internal/external temperature.

The internal air movement comes from buoyancy forces generated by differences in internal temperature and by dynamic forces at the input and output openings.

\section{Description Of Wind Towers}

Wind tower is a formal structure element of Iranian architecture that is used to transmit the wind to the interior spaces of buildings to provide thermal comfort for occupants. Wind tower in Iranian architecture is a combination of inside and outside building [11].

The wind tower catches the prevailing wind that flows at a higher speed relative to the ground, directing it down the tower. The air velocity increases down until it reaches its maximum value at the discharge opening of the tower which is at the same time the air injection orifice in the building. The air flows in the space occupied by the inhabitants providing natural ventilation and leaves the building through openings, doors and windows.

In the night time, the operation of the wind tower will be reversed or it acts as a chimney (stack effect). The indoor air (less dense) leaves the building through the tower. It will be replaced by outside air (denser) that enters through the openings and windows.

\subsection{Numerical Modeling}

\section{Materials And Methods}

The equations governing the wind flow in the neutral and stable atmospheric boundary layer $\mathrm{ABL}$ are:

$$
\begin{aligned}
& \frac{\partial u}{\partial t}+\left(u \frac{\partial u}{\partial x}+v \frac{\partial u}{\partial y}\right)+\frac{1}{\rho} \frac{\partial p}{\partial x}=f V \\
& \frac{\partial v}{\partial t}+\left(u \frac{\partial v}{\partial x}+v \frac{\partial v}{\partial y}\right)+\frac{1}{\rho p} \frac{\partial p}{\partial y}=-f U \\
& \rho\left(\frac{\partial u}{\partial x}+\frac{\partial v}{\partial y}\right)=0
\end{aligned}
$$

Liquids and gas flowing at low speeds behave like incompressible fluids [12]. The governing equations for an incompressible fluid such as atmospheric air in the rigorous sub-layer then become:

\subsubsection{Conservation of mass [13] :}

$$
\begin{aligned}
& \frac{\partial x}{\partial x}+\frac{\partial D}{\partial y}=0 \\
& \frac{\partial u^{y}}{\partial x}+\frac{\partial v^{y}}{\partial y}=0 \\
& \frac{\partial u}{\partial x}+\frac{\partial V}{\partial y}=0
\end{aligned}
$$

\subsubsection{Navier-Stokes equations [13] :}

$$
\begin{aligned}
& \frac{\partial(\rho u)}{\partial t}+\frac{\partial(\rho u u)}{\partial x}+\frac{\partial(\rho w)}{\partial y}=-\frac{\partial p}{\partial x}+\mu\left(\frac{\partial^{2} u}{\partial x^{2}}+\frac{\partial^{2} u}{\partial y^{2}}\right) \\
& \frac{\partial(\rho v)}{\partial t}+\frac{\partial(\rho u v)}{\partial x}+\frac{\partial(\rho w)}{\partial y}=-\frac{\partial p}{\partial y}+\mu\left(\frac{\partial^{2} v}{\partial x^{2}}+\frac{\partial^{2} v}{\partial y^{2}}\right)
\end{aligned}
$$


The most important factor influencing the ventilation capacity of the wind tower is the internal pressure field induced by the wind strongly influenced by the geometry of the tower and the wind direction relative to the opening of the latter [14].

The surface pressure coefficient of a building is defined by:

$$
\mathbf{C p}=\left(\mathbf{P}-\mathbf{P}_{0}\right) /\left(0.5 \square \mathbf{v}^{2}\right)
$$

With $\mathrm{P}$ is the local pressure $(\mathrm{Pa}) . \mathrm{P}_{0}$ represents the static pressure $(\mathrm{Pa})$ and $\mathrm{v}_{0}$ is the reference velocity of the air $(\mathrm{m} / \mathrm{s}), \rho$ is the air density $(\mathrm{kg} / \mathrm{m} 3)$.

To demonstrate the effect of wind and its direction on the external pressure field and consequently the ventilation capacity of the wind tower, external aerodynamic shape of the face in windward of the tower is questioned. Three new aerodynamic forms are studied: circular, triangular, the $\mathrm{U}$ shape and traditional square shape (Fig. 2).

\subsection{Geometry}

The exterior field is entirely composed of atmospheric air. The dimensions of the field are chosen according to the recommendations of Revuz [15] to avoid the blockage effect on simulation results. The blockage effect rate is defined as the ratio between the face of the exterior domain and the wind tower face which must not exceed $3 \%$. In our case, the blockage effect is equal to $0.89 \%$.

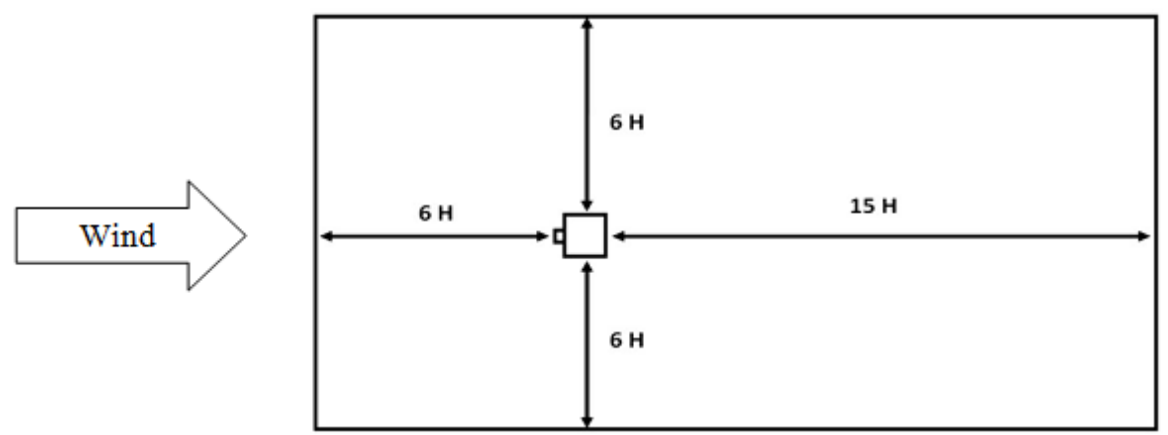

Fig. 2 Dimensions of the exterior domain with $\mathrm{H}=9 \mathrm{~m}$.

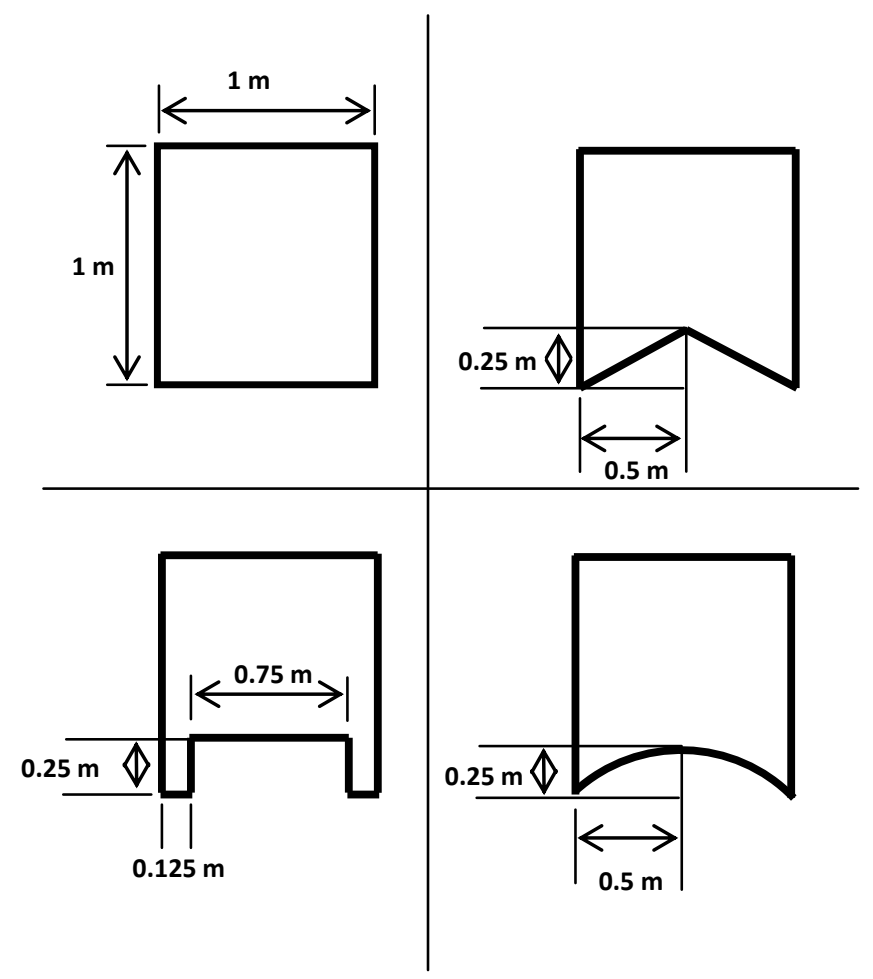

Fig. 3 Cross sections of the tower studied wind: square, triangular, circular, and U. 


\subsection{Mesh}

An unstructured triangular mesh is used in the study with refinement at the wind tower to take the interaction between wind and walls of the tower into consideration. This mesh type choice is due to the geometric complexity of the triangular, circular, and $\mathrm{U}$ aerodynamic forms. The triangular mesh covers every detail of these geometries (Fig. 4).
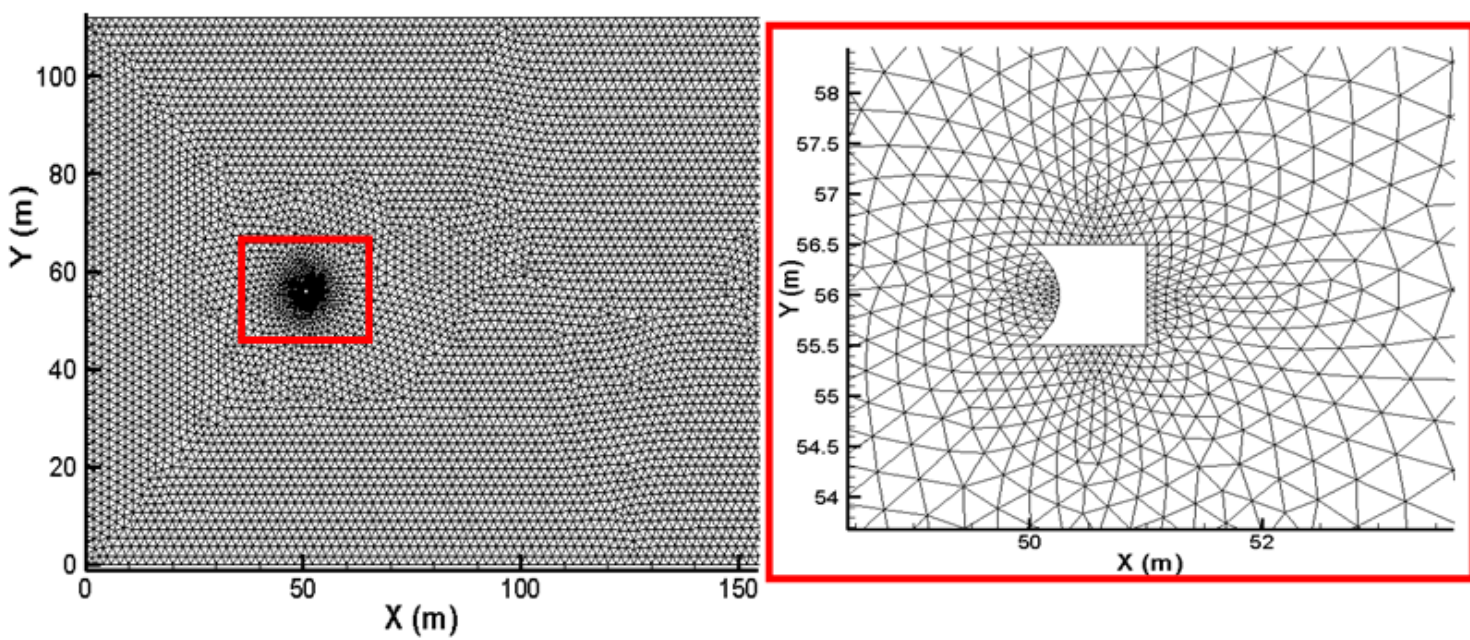

Fig.4 Unstructured triangular mesh with a refinement at the wind tower location.

\subsection{Boundary conditions and initial conditions}

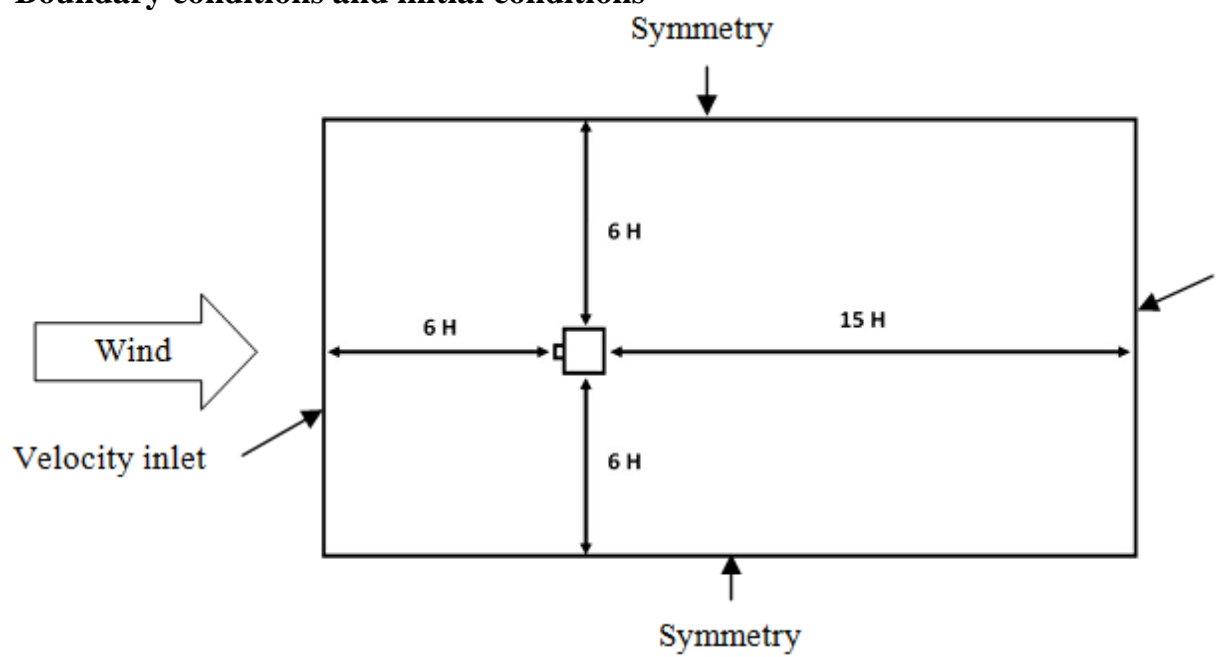

Pressure outlet

Fig.5 Boundary conditions

The walls of the tower are smooth and adiabatic. For initials conditions, the wind speed is $3 \mathrm{~m} \cdot \mathrm{s}^{-1}$ chosen according to the climatic conditions of the town of Bechar (South-West of Algeria) and in X axis direction only $\left(\mathrm{v}_{\mathrm{y}}=0\right)$. The standard $\mathrm{k}-\varepsilon$ model is used in the simulation due to the good agreement with this wind engineering case. 


\section{Results And Discussion}
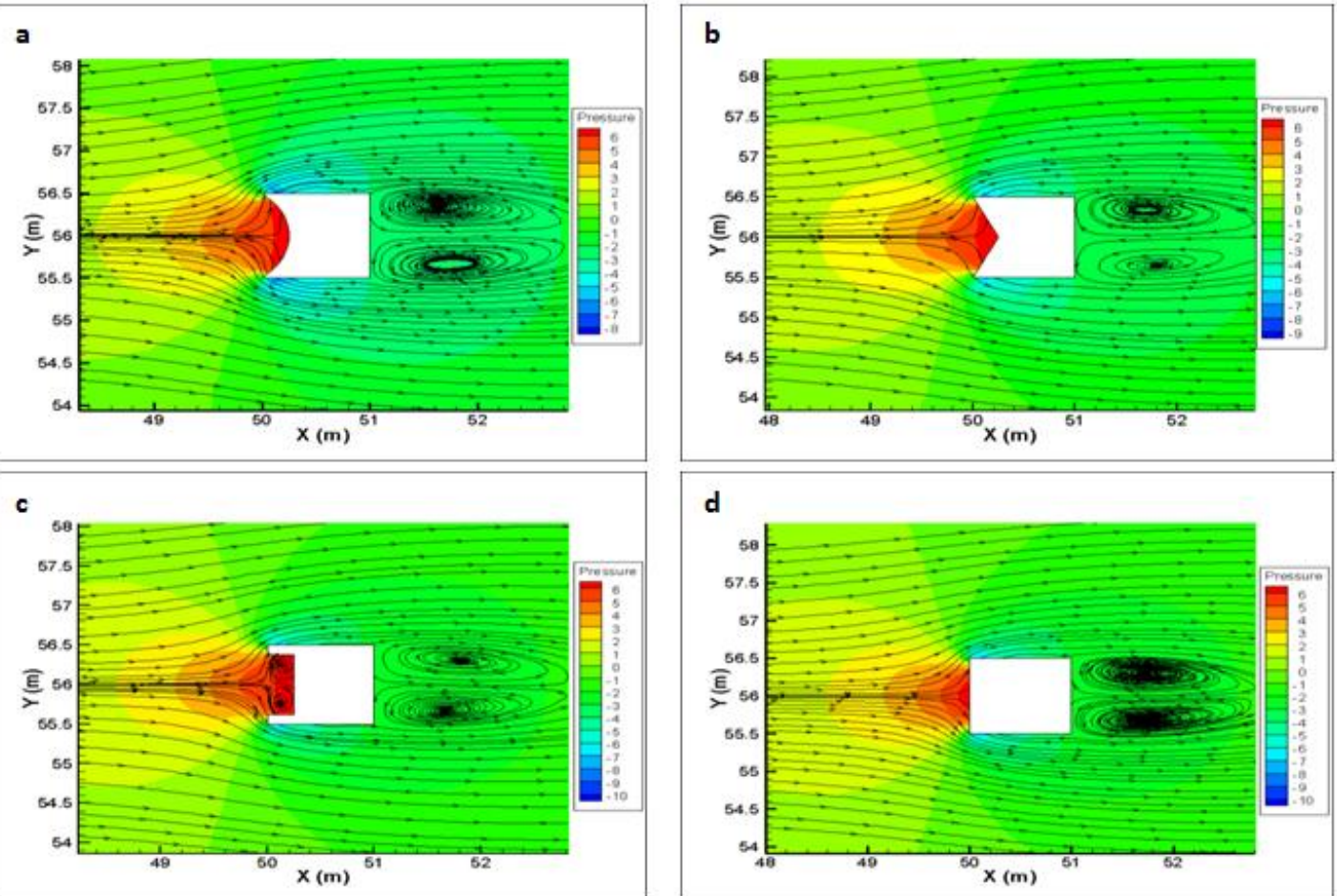

Fig. 6 Total pressure $(\mathrm{Pa})$ for 4 models: circular, triangular, square and $\mathrm{U}$.
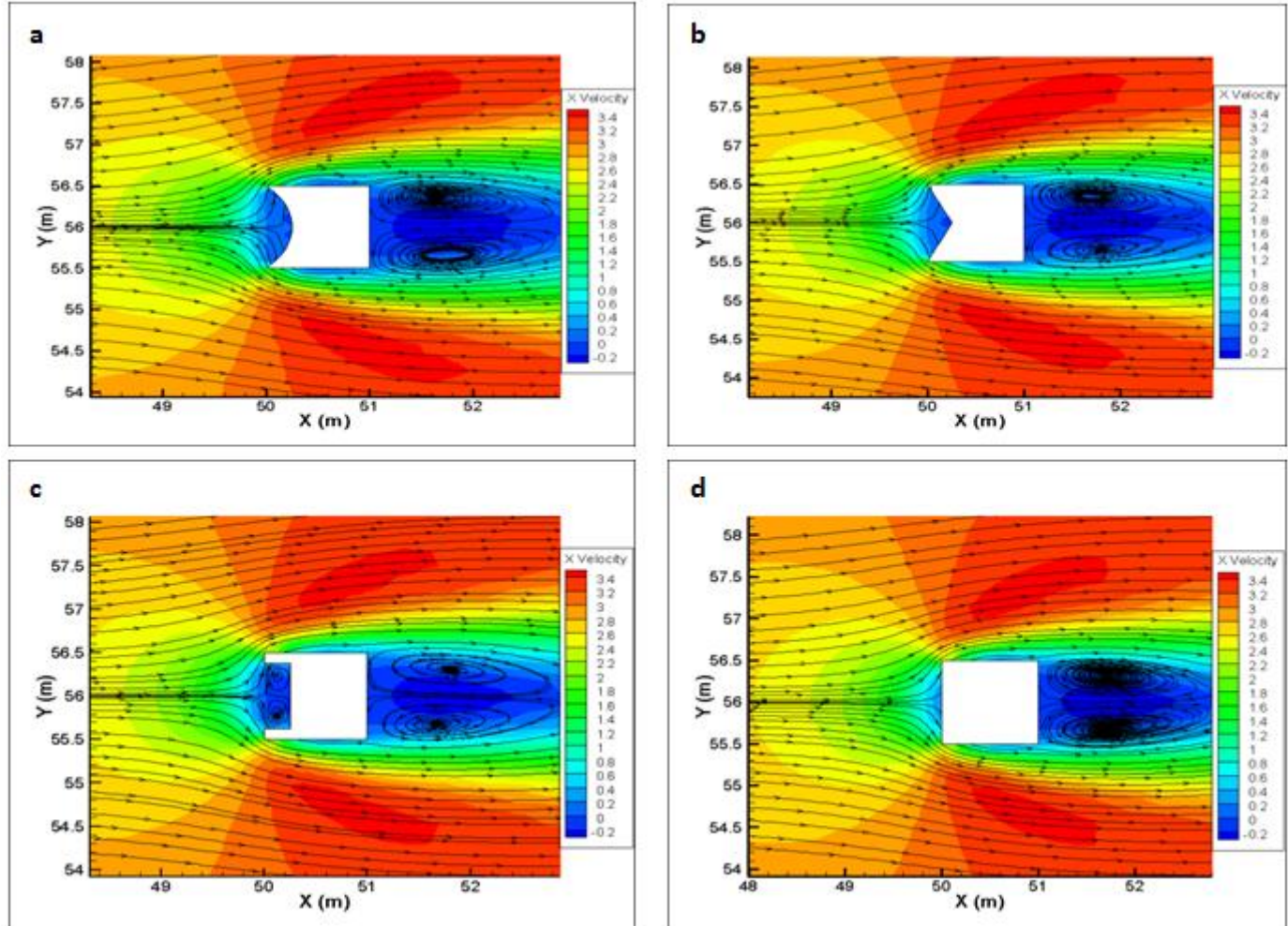

Fig. 7 Average speed (m/s) for 4 models: circular, triangular, $\mathrm{U}$ and square. 

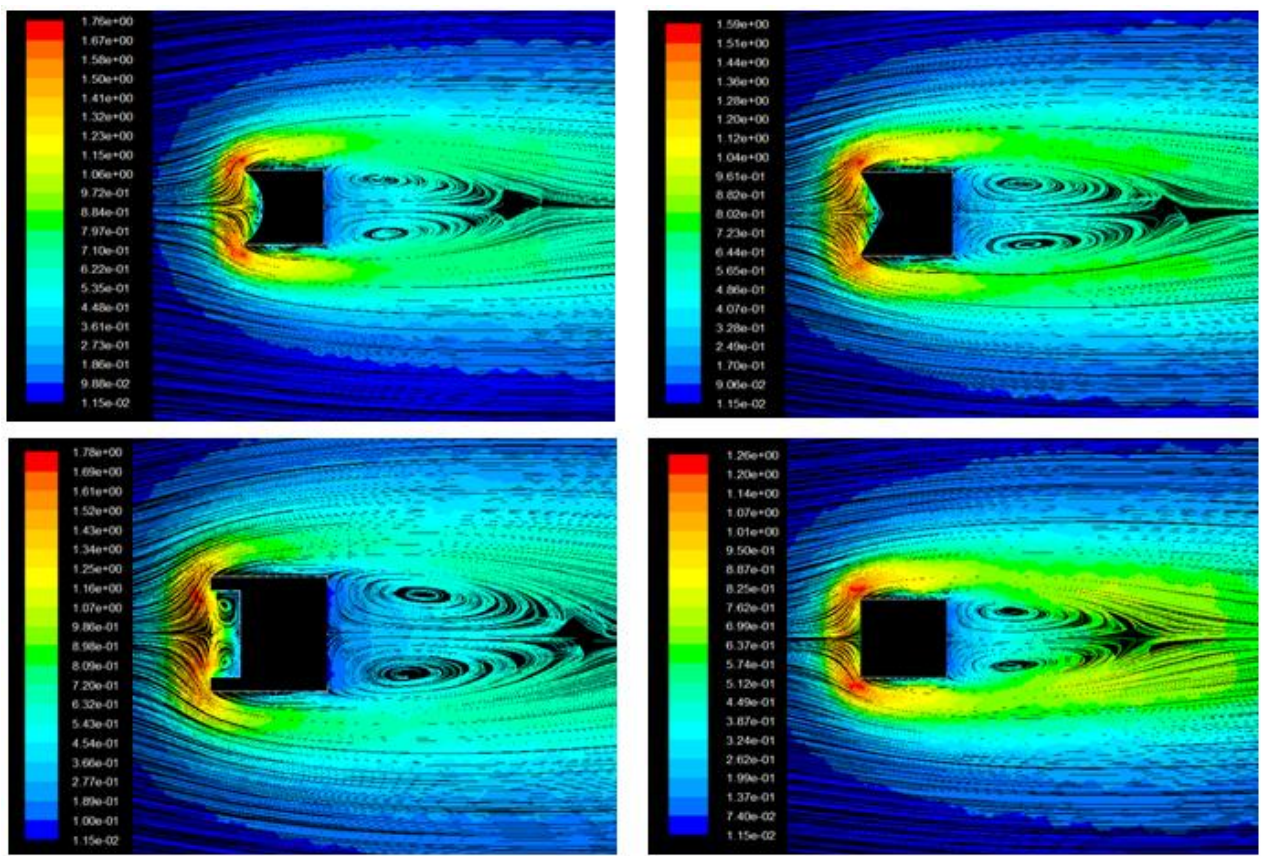

Fig. 8 Turbulent kinetic energy $\mathrm{m}^{2} / \mathrm{s}^{2}$ for 4 models circular, triangular, $\mathrm{U}$ and square.
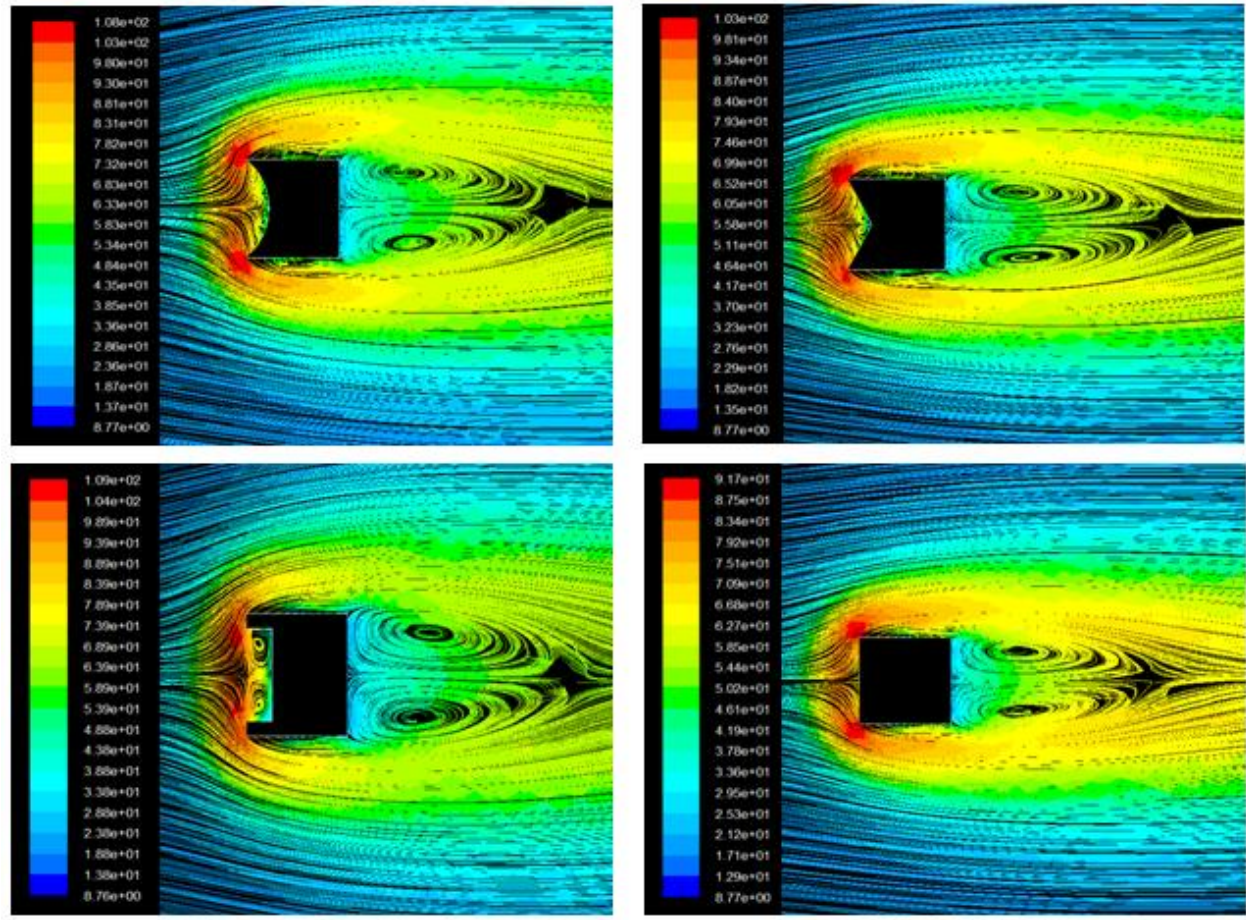

Fig. 9 Turbulence Intensity (\%) for 4 models: circular, triangular, square and U

The obtained simulation results show that the 4 aerodynamic forms have a positive pressure in the windward and a negative pressure in the leeward of the wind tower. It is also important to mention the existence of a recirculation zone of flow in this zone. Another detachment area of flow in the two lateral sides of the wind tower exists in four studied models and the size of this area change from one model to another.

The circular and triangular model have the greatest negative pressure region and also critical areas in the lateral sides because of flow detachment in these areas (Fig. 10) with pressure drop (-7 to -6 Pa). Pressure drop region is greater in the circular model in comparison with triangular model.

A new recirculation flow zone exist in the $U$ model due to the geometric shape that plays the role of obstacle which forces the flow to recirculate it before leaving this zone.

The pressure coefficient of the wind tower is greater in the square and U model (10.7) than the circular and triangular model (10.2). 
The area where the wind speed becomes a minimum (almost $0 \mathrm{~m} / \mathrm{s}$ ) is available in three models, causing a large flow stagnation area and therefore a large positive pressure region in comparison with the traditional shape (square and rectangular).

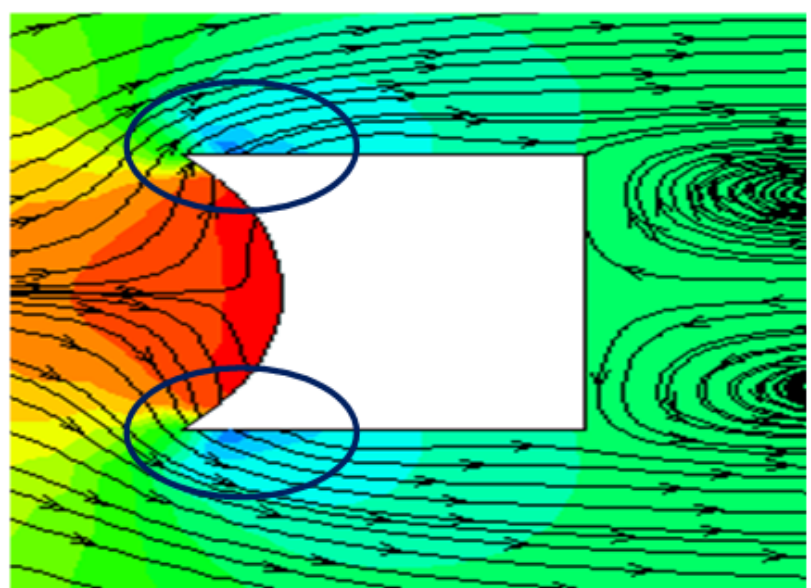

Fig.10 The regions of the pressure drop in the circular model.

\section{Conclusion}

Natural ventilation by wind towers is an effective technique used in the past and the present to ensure thermal comfort especially in hot arid regions.

The aerodynamic shape of the windward wall of a traditional wind tower is studied in this paper. The traditional wind tower often uses rectangular and square shapes. 3 new models are studied: circular, triangular and the U shape

The results confirm the importance of the geometry of the wind tower to improve the performance of this technique. In comparison with the square model, the two circular and triangular models have external and internal pressures much higher than the square and $\mathrm{U}$ model. Higher pressure difference between the inside and outside of the wind tower leads to better natural ventilation performance of the device. The results can improve the performance of both traditional and commercial (modern) wind towers.

\section{References}

[1] B.MOUJALLED. 2007. Dynamic modeling of thermal comfort in naturally ventilated buildings. Doctorat thesis. The Institute of Applied Sciences in Lyon.France.

[2] Agency of Promotion and Rationalization of the Use of Energy APRUE.[Online] http://www.aprue.org.dz/

[3] J. K. Calautit, B. R. Hughes, S.S. Shahzad, 2015; CFD and wind tunnel study of the performance of a uni-directional wind catcher with heat transfer devices, Renewable Energy 83 85-99.

[4] Wang Liping, Wong Nyuk Hien, Applying Natural Ventilation for Thermal Comfort in Residential Buildings in Singapore, Department of Building, National University of Singapore, 4 Architecture Drive, Singapore 117566, Architectural Science Review Volume 50.3, pp 224-233.

[5] David Etheridge, 2011; Natural ventilation of buildings; Natural Ventilation of Buildings: Theory, Measurement and Design. Department of architecture and built environment, University of Nottingham, UK, Edition Wiley.

[6] X.Yang, K. Zhong, Y. Kang, T. Tao, 2015; Numerical investigation on the airflow characteristics and thermal comfort in buoyancydriven natural ventilation rooms, Energy and Buildings 109 255-266.

[7] H. Pabiou, J. Salort, C. Ménézo , F. Chillà, 2015;Natural cross-ventilation of buildings, an experimental study, 6th International Building Physics Conference, IBPC 2015, Energy Procedia 782911 - 2916.

[8] Z. (John) Zhai, M. El Mankibi, A. Zoubir, 2015; Review of natural ventilation models. 6th International Building Physics Conference, IBPC 2015, Energy Procedia 78 2700 - 2705.

[9] C.R. Chu, Y.W. Wang, 2010; The loss factors of building openings for wind-driven ventilation, Department of Civil Engineering, National Central University, Taiwan, Building and Environment 45 2273-2279.

[10] David Etheridge, 2015; A perspective on fifty years of natural ventilation research, The University of Nottingham (Retired), UK, Building and Environment 91 51-60.

[11] 2012, Study of Wind Catchers with square plan: Influence of physical parameters. International Journal of Modern Engineering Research (IJMER)

[12] Tong Yang; Mai 2004, CFD and essays on natural ventilation lot of a large-scale building; Doctoral thesis ; University of Nottingham England.

[13] Matthew Peter Straw, Mars 2000.Computation and Measurement of Wind Induced Ventilation Thèse de doctorat ; Université de Nottingham ; Angleterre ;

[14] M. N. Kasbadji ; 2006; Evaluation of the contribution wind energy deposit has the vertical profiling of wind velocity in Algeria; PhD thesis, University of Tlemcen.

[15] Julia Revuz, 2011, Numerical simulation of the wind flow around a tall building and its dynamic response to wind excitation, PhD Thesis, Department of Civil Engineering, Faculty of Engineering, University of Nottingham, UK. 